
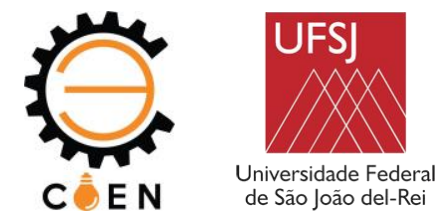

\title{
MATERIAL COMPÓSITO DE MATRIZ CIMENTÍCIA REFORÇADO COM PARTÍCULAS DE CARBETO DE SILÍCIO PARA APLICAÇÃO COMO RESTRITOR POROSO EM MANCAIS AEROSTÁTICOS
}

\author{
Heitor Camargo Melo ${ }^{(1)}$ (heitorcmelo@outlook.com), Leandro José da Silva ${ }^{(2)}$ (leandro.silva@ufsj.edu.br) \\ (1) Universidade Federal de São João del-Rei (UFSJ) - PPMEC - Praça Frei Orlando, 170, Centro, São João del-Rei, Minas Gerais \\ (2) Universidade Federal de São João del-Rei (UFSJ) - DEMEC - Praça Frei Orlando, 170, Centro, São João del-Rei, Minas Gerais
}

RESUMO: $O$ principal objetivo deste trabalho é investigar a influência da adição de carbeto de silício (SiC) e da pressão de compactação nas propriedades físicas e mecânicas de um compósito de matriz cimentícia, com o propósito de desenvolver um material que apresente níveis de porosidade e resistência mecânica adequados para sua utilização em um mancal aerostático. A metodologia de planejamento fatorial completo foi utilizada para estudar os efeitos da variação da fração mássica de SiC e da pressão de compactação sobre a densidade volumétrica, porosidade aparente, resistência à flexão e módulo de elasticidade estático dos compósitos. Os experimentos preliminares foram conduzidos avaliando-se três níveis para a adição de micropartículas de $\mathrm{SiC}(20 \%$, 30\% e 40\%) e três níveis de compactação dos compósitos (10 MPa, $20 \mathrm{MPa}$, e $30 \mathrm{MPa}$ ). Os resultados preliminares revelam que tanto o percentual de $\mathrm{SiC}$ quanto a pressão de compactação, além da interação entre os fatores, têm influência significativa nos resultados das propriedades estudadas.

PALAVRAS-CHAVE: Carbeto de silício, Compósito cimentício, Mancais aerostático, Compactação uniaxial.

\section{INTRODUÇÃO}

Mancais são definidos como dispositivos que permitem o movimento relativo entre duas superfícies. Os modelos de mancais mais conhecidos e utilizados são os mancais de rolamento, que utilizam elementos rolantes para permitir o movimento por contato direto. Mancais aerostáticos utilizam de uma fina camada de ar pressurizado para realizar a lubrificação do contato entre as partes. Quando usado como lubrificante, o gás em alta pressão gera coeficientes de atrito muito baixos, podendo chegar ao atrito zero (SILVA, 2015).

Os mancais aerostáticos podem ser classificados como cilíndricos, axiais com movimentos circulares ou lineares, esféricos e cônicos (MUNDAY, 1971). Embora apresentem diversas formas construtivas, o princípio de funcionamento não difere. $\mathrm{O}$ ar é pressurizado sobre um (ou vários) orifício(s), criando um diferencial de pressão entre as superfícies, promovendo a separação delas por um filme de gás e permitindo o movimento relativo entre elas (FOURKA E BOINS, 1997). O fluxo de ar por orifícios usinados no restritor do mancal gera uma variação heterogênea da pressão ao longo da superfície de contato (KWAN, 1996).

Quando se utiliza um material poroso como constituinte do restritor de um mancal aerostático pode se obter uma distribuição mais homogênea da pressão no filme de gás do mancal, permitindo melhor desempenho quanto à capacidade de carga, rigidez e características de amortecimento (SILVA, 2015). Na Figura 1 são ilustradas as diferenças entre os perfis de pressão exercida pelo fluxo de ar para os restritores de orifícios e poroso, em que, para o segundo, pode ser observado o perfil mais uniforme e homogêneo, o que resulta em melhor desempenho. Para ser 

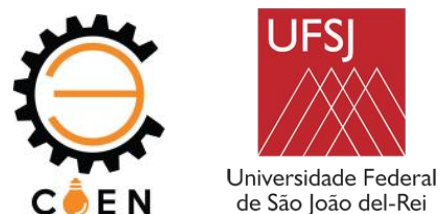

utilizado como restritor poroso, o material cerâmico deve apresentar entre $20 \%$ e $35 \%$ de porosidade aberta (KWAN, 1996). Entretanto, independente do volume de poros, estes devem apresentar conectividade adequada, se forma que o material seja permeável pelo gás lubrificante (SILVA, 2015).

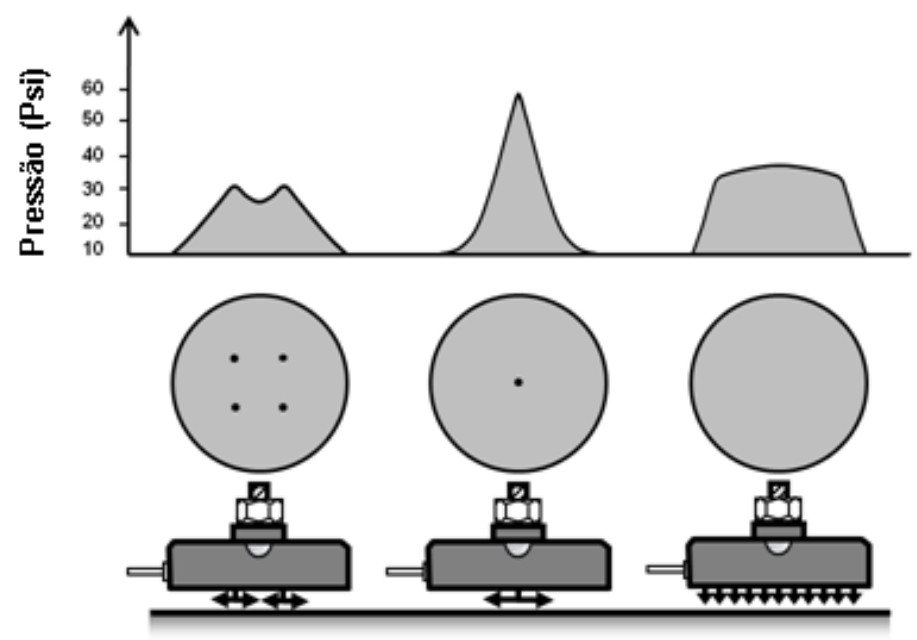

FIGURA 1. Perfis de pressão para mancais aerostáticos axiais com diferentes restritores: múltiplos orifícios, orifício central e material poroso, da esquerda para a direita. Fonte: (SILVA, 2015).

O cimento Portland mostra-se promissor para fabricação de restritores porosos de mancais aerostáticos e apresenta baixo custo por não precisar de altas temperaturas para se solidificar. Os materiais cimentícios quando misturados com água formam uma pasta que enrijece e endurece, propiciando que estruturas com praticamente qualquer forma sejam moldadas rapidamente (PANZERA, 2007). Para que os compósitos de cimento possam suportar as elevadas pressões exercidas pelo fluxo de ar estes podem ser reforçados com fibras sintéticas, micropartículas e/ou nanopartículas, estas últimas atuando na melhoria do controle da porosidade do concreto (SILVA, 2015). Panzera (2007) estudou os efeitos da adição de microssílica $\left(\mathrm{SiO}_{2}\right)$ como fase reforçadora em compósito cimentício, aplicando compactação uniaxial, gerando um material com propriedades físicas e mecânicas comparáveis às dos materiais comumente usados em restritores porosos, mostrando-se, ainda, com menor custo de fabricação e de matéria prima. Panzera et al. (2013) mostraram que, para compósitos cimentícios, níveis de porosidade superiores a $15 \%$ proporcionaram permeabilidade suficiente para produzir um filme gasoso de $5 \mu \mathrm{m}$ de espessura, quando utilizado como restritor poroso em mancal aerostático. Silva (2015) estudou os efeitos da adição de nanotubos de carbono à pasta cimentícia, que promoveu melhoria nas propriedades físicas e mecânicas, como permeabilidade e resistência à compressão, além de estudar o uso de aditivo superplastificante na mistura, que permite reduzir a quantidade de água necessária para a hidratação do cimento. A adição de superplastificante gerou um refinamento na estrutura de poros do material, melhorando a dispersão dos nanotubos na matriz cimentícia. O compósito fabricado com a adição de aditivo superplastificante e reforçado com nanotubos de carbono apresentou níveis de coeficiente de permeabilidade e de resistência mecânica satisfatórios para a aplicação em restritores porosos. 

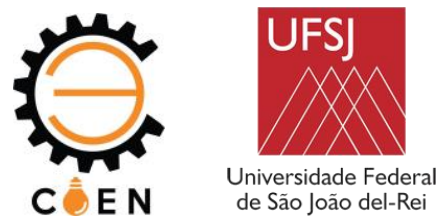

O carbeto de silício $(\mathrm{SiC})$ foi sintetizado industrialmente pela primeira vez em 1894, e era usado como abrasivo e como partes refratárias em fornos de altas temperaturas. Desde então, o SiC tem se tornado um material muito importante, amplamente usado na fabricação de semicondutores, como revestimento de peças para usinagem de alta precisão e em filtros de partículas diesel (TANAKA, 2011). Compósitos cerâmicos reforçados com partículas de SiC apresentam uma vida útil em ensaios de fluência até dez vezes maior, e deformação até a ruptura até oito vezes menor. Este efeito ocorre devido às partículas de $\mathrm{SiC}$ inibirem a nucleação de vacâncias durante a sinterização (OHJI et al., 1996). Compósitos cerâmicos laminados, reforçados com micropartículas de $\mathrm{SiC}$, em até $40 \%$ de fração volumétrica, tiveram suas resistências à tração, à flexão e à fratura aumentadas consideravelmente. As partículas aumentam a resistência da matriz impedindo a propagação de trincas devido à boa adesão interfacial, consequentemente aumentando a resistência do compósito como um todo (XIE, 2015). Bahari (2016) estudou a influência da adição de nanopartículas de $\mathrm{SiC}$ à pasta cimentícia, bem como a influência do tempo de hidratação. As partículas de $\mathrm{SiC}$ proporcionaram aumentos significativos na resistência à compressão e à flexão do compósito, pois estas geraram uma mudança na estrutura cristalina do cimento, inibindo a formação de estruturas distorcidas e aumentando a formação de estruturas amorfas. O tempo de hidratação do compósito também mostrou influência nas propriedades mecânicas, onde um período de hidratação de 28 dias apresentou os melhores resultados para estas propriedades.

A motivação deste trabalho é investigar a concentração de carbeto de silício utilizado como fase dispersa em compósito de matriz cimentícia, e a pressão de compactação durante a fabricação dos corpos de prova, e suas influências nos resultados finais de densidade volumétrica, porosidade aparente, resistência à flexão e módulo de elasticidade estático, a fim de desenvolver um material com devidas propriedades para aplicação como restritores porosos de mancais aerostáticos. A aplicação de uma análise estatística foi feita para melhor compreensão dos resultados.

\section{OBJETIVOS}

O objetivo principal deste trabalho será desenvolver e investigar o desempenho estrutural e o comportamento físico de um material compósito com matriz cimentícia reforçada com partículas de Carbeto de Silício, referentes à aplicação como restritor poroso para mancais aerostáticos axiais.

\subsection{Objetivos Específicos}

Os objetivos específicos deste projeto são:

- Realizar testes com diversas composições do material compósito, variando a fração mássica de partículas reforçadoras, para encontrar a que proporciona melhores propriedades para a finalidade;

- Identificar os efeitos de diversas pressões de compactação durante a fabricação dos corpos de prova, a fim de encontrar a que entregue melhores propriedades ao produto final;

- Aplicar métodos estatísticos de planejamento de experimentos, DOE (Design of Experiment) e ANOVA (Analysis of Variance), para identificar os efeitos dos fatores experimentais nas propriedades do material final. 

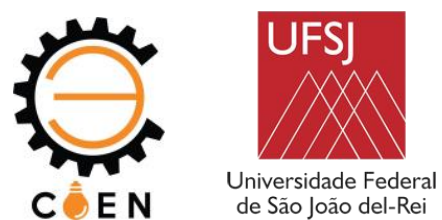

- Analisar o desempenho estrutural (propriedades mecânicas de resistência e rigidez) e as propriedades físicas adequadas à aplicação pretendida (porosidade, permeabilidade) dos materiais estudados neste trabalho; e por fim analisar o desempenho final do(s) material(is) (mais adequado(s)) como restritor no mancal aerostático.

\section{MATERIAIS E MÉTODOS}

\subsection{Planejamento experimental}

A metodologia de Planejamento de Experimentos (DOE) foi utilizada neste trabalho, adotando-se um planejamento fatorial completo do tipo $3^{2}$ (dois fatores, cada um em três níveis). Neste estudo foram utilizados como fatores experimentais o percentual de carbeto de silício $(\% \mathrm{SiC})$, em relação à massa seca do cimento, e a pressão de compactação (Comp) à qual o corpo de prova foi submetido durante sua moldagem. Cada fator foi estudado em três níveis, totalizando 9 condições experimentais. Foram adotadas 4 repetições para cada condição experimental, totalizando 36 corpos de prova. As combinações experimentais são mostradas na Tabela 1. A fabricação e os ensaios foram conduzidos de forma aleatória para minimizar a inserção de erro devido às condições não controláveis, permitindo que o experimento seja replicável.

As variáveis respostas estudadas foram: Densidade volumétrica (Den); Porosidade aparente (Pap); Resistência à flexão (RF); Módulo de elasticidade estático (MEE). As condições experimentais foram denominadas por um código, onde a letra $C$, seguida pelo número 20,30 ou 40 representa o percentual de carbeto de silício em relação à massa seca de cimento que foi utilizada na mistura, e a letra $\mathrm{P}$, seguida pelo número 10,20 ou 30 , representa a pressão de compactação a qual o corpo de prova foi submetido.

Tabela 1. Condições experimentais do planejamento fatorial $3^{2}$.

\begin{tabular}{lcc}
\hline Condição & \%SiC & Pressão de Compactação - Comp (Mpa) \\
\hline C20P10 & 20 & 10 \\
C20P20 & 20 & 20 \\
C20P30 & 20 & 30 \\
C30P10 & 30 & 10 \\
C30P20 & 30 & 20 \\
C30P30 & 30 & 30 \\
C40P10 & 40 & 10 \\
C40P20 & 40 & 20 \\
C40P30 & 40 & 30 \\
\hline
\end{tabular}

\subsection{Fabricação}

Inicialmente as partículas de $\mathrm{SiC}$ foram secas em estufa a $80^{\circ} \mathrm{C}$ durante 24 horas, visando eliminar a influência da umidade do carbeto de silício na hidratação do concreto. Após a secagem, foi realizado o peneiramento em malha 100 mesh, visando desfazer aglomerados das partículas. 

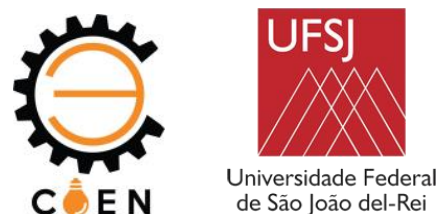

Após este procedimento as partículas foram embaladas em recipiente fechado para não absorverem umidade até serem utilizadas para a fabricação dos compósitos.

Os corpos de prova foram fabricados a partir da mistura do cimento Portland CP V com água (usando uma relação água/cimento constante de 0,25; em massa), e partículas de carbeto de silício (SiC). As proporções das misturas seguiram as condições listadas na Tabela 1.

Para a moldagem dos corpos de prova, os componentes foram pesados e, inicialmente, em um recipiente, misturou-se manualmente as partículas de $\mathrm{SiC}$ e o cimento, durante 2 minutos. Após a homogeneização dos componentes sólidos a água foi adicionada, misturando-se manualmente por 2 minutos. Após a mistura manual, a argamassa foi então levada a um misturador mecânico por 3 minutos. A mistura foi vazada em um molde metálico para ensaio de flexão (Figura 2), e submetida à compactação axial em prensa hidráulica por 1 minuto, de acordo com a pressão específica estabelecida para cada condição experimental. Após a compactação, o corpo de prova foi retirado do molde e envolvido em filme de PVC, para evitar a perda de água para o ambiente. Os corpos de prova embalados desta forma foram reservados por 28 dias, para que ocorresse a hidratação completa do cimento, e após este período foram preparados para os ensaios físicos e mecânicos.

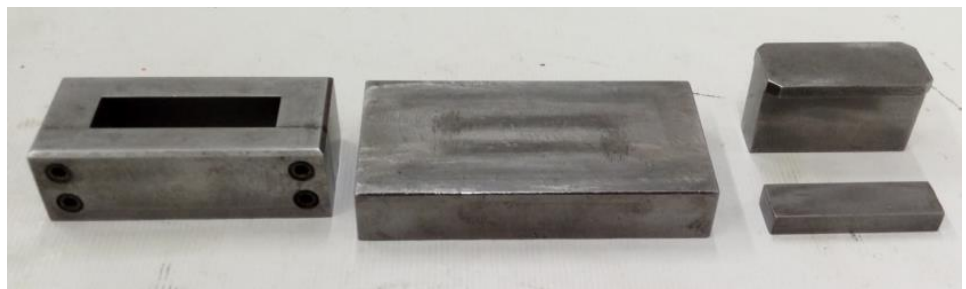

Figura 2. Molde metálico para fabricação dos corpos de prova.

\subsection{Variáveis respostas}

\subsubsection{Densidade volumétrica}

Após o período de hidratação os corpos de prova foram pesados e tiveram suas dimensões comprimento, largura e espessura determinadas. Para determinar a densidade dos corpos de prova foram utilizados uma balança de precisão (resolução de $0,01 \mathrm{~g}$ ) para a medição da massa e um paquímetro digital (resolução de $0,01 \mathrm{~mm}$ ) para efetuar a medição indireta do volume do corpo de prova, que sendo um paralelepípedo, tem seu volume dado pela Equação 1:

$$
V=b d l
$$

Onde:

$V$ é o volume do corpo de prova;

$b$ é a largura do corpo de prova;

$d$ é a espessura do corpo de prova;

$l$ é o comprimento do corpo de prova.

A densidade volumétrica pôde, então, ser determinada através da Equação 2: 


$$
\rho_{V}=\frac{m}{V}
$$

Onde:

$\rho_{V}$ é a densidade volumétrica do corpo de prova;

$m$ é a massa do corpo de prova;

$V$ é o volume do corpo de prova.

\subsubsection{Porosidade aparente}

Para ser realizado o ensaio de porosidade aparente, os corpos de prova foram pesados previamente, e depois submergidos em água pelo período de 24 horas, para que os poros abertos fossem preenchidos com água. Então, os corpos de prova saturados foram pesados submersos, e pesados novamente fora do recipiente com água. A porosidade aparente pôde então ser calculada através da Equação 5:

$$
P_{a p}=\frac{m_{2}-m_{1}}{m_{2}-m_{3}} \times 100
$$

Onde:

$P_{a p}$ é a porosidade aparente do corpo de prova;

$m_{1}$ é a massa do corpo de prova seco;

$m_{2}$ é a massa do corpo de prova saturado;

$m_{3}$ é a massa do corpo de prova saturado submerso.

\subsubsection{Resistência à flexão}

Foi realizado um ensaio de flexão em três pontos, em uma máquina de ensaios universal Shimadzu com célula de carga Shimadzu modelo AM-X com capacidade para $100 \mathrm{kN}$. Os corpos de prova foram ensaiados a uma velocidade de deslocamento de $1 \mathrm{mms}^{-1}$ e com distância entre apoios de 40mm, como sugerido pela norma ASTM C1161-13. A resistência à flexão foi calculada através da Equação 3:

$$
S=\frac{3 P L}{2 b d^{2}}
$$

Onde:

$S$ é a resistência à flexão;

$P$ é a carga de ruptura do corpo de prova;

$L$ é a distância entre apoios;

$b$ é a largura do corpo de prova;

$d$ é a espessura do corpo de prova. 


\subsubsection{Módulo de elasticidade estático}

O módulo de elasticidade estático pode ser calculado através da Equação 4:

$$
E=\frac{\Delta_{\sigma}}{\Delta_{\varepsilon}}
$$

Onde:

E é o módulo de elasticidade estático do corpo de prova; $\Delta \sigma$ é a variação da tensão aplicada sobre o corpo de prova; $\Delta \varepsilon$ é a variação da deformação sofrida pelo corpo de prova.

Os dados para calcular o módulo de elasticidade estático foram obtidos através das curvas de tensão/deformação, obtidas no ensaio de flexão em três pontos.

\section{RESULTADOS E CONCLUSÕES}

Os resultados obtidos para as propriedades físicas e mecânicas foram analisados utilizando a metodologia estatística de Análise de Variância (ANOVA), adotando-se um nível de significância de $0,05(5 \%)$ para o teste de hipóteses. Os resultados da ANOVA são exibidos na Tabela 3, onde são listados os P-valores dos testes de hipóteses, e o coeficiente de determinação, $\mathrm{R}^{2}$. Adicionalmente, são também exibidos na Tabela 3 os resultados dos testes de normalidade de Anderson-Darling, usados para verificar a predisposição dos dados em seguir distribuição normal de probabilidade. Neste caso, o P-valor deve ser maior que o nível de significância adotado $(0,05)$, visto que a hipótese nula do teste é a de que os dados não seguem distribuição normal.

Tabela 3. Resultados da ANOVA.

\begin{tabular}{ccccc}
\hline Fatores & Den & Pap & RF & MEE \\
\hline$\% \mathrm{SiC}$ & 0,000 & 0,000 & 0,000 & 0,000 \\
Comp & 0,000 & 0,000 & 0,000 & 0,000 \\
$\%$ SiC ${ }^{*}$ Comp & 0,018 & 0,001 & 0,011 & 0,783 \\
Anderson-Darling & 0,371 & 0,508 & 0,529 & 0,776 \\
$\mathrm{R}^{2}$ & $98,13 \%$ & $98,73 \%$ & $81,09 \%$ & $77,46 \%$ \\
\hline
\end{tabular}

Os resultados da Tabela 3 mostram que os fatores, atuando isoladamente, apresentam influência significativa em todas as variáveis respostas, devido aos P-valores serem menores que o nível de significância do método (P-valor < 0,05). A interação de segunda ordem dos fatores não apresenta influência significativa somente para o módulo de elasticidade estático, pois o resultado de seu P-valor é maior que o nível de significância do método. Os resultados dos testes de Anderson-Darling, por serem maiores que o nível de significância do método, mostram que existe distribuição normal nos resíduos, validando a ANOVA. Os valores de $\mathrm{R}^{2}$ mostram que o modelo possui boa capacidade preditiva da variabilidade. 


\subsection{Densidade volumétrica}

A Figura 3 exibe o gráfico de efeitos de interação entre os fatores fração mássica de micropartículas de carbeto de silício e pressão de compactação uniaxial sobre a média da densidade volumétrica dos compósitos.

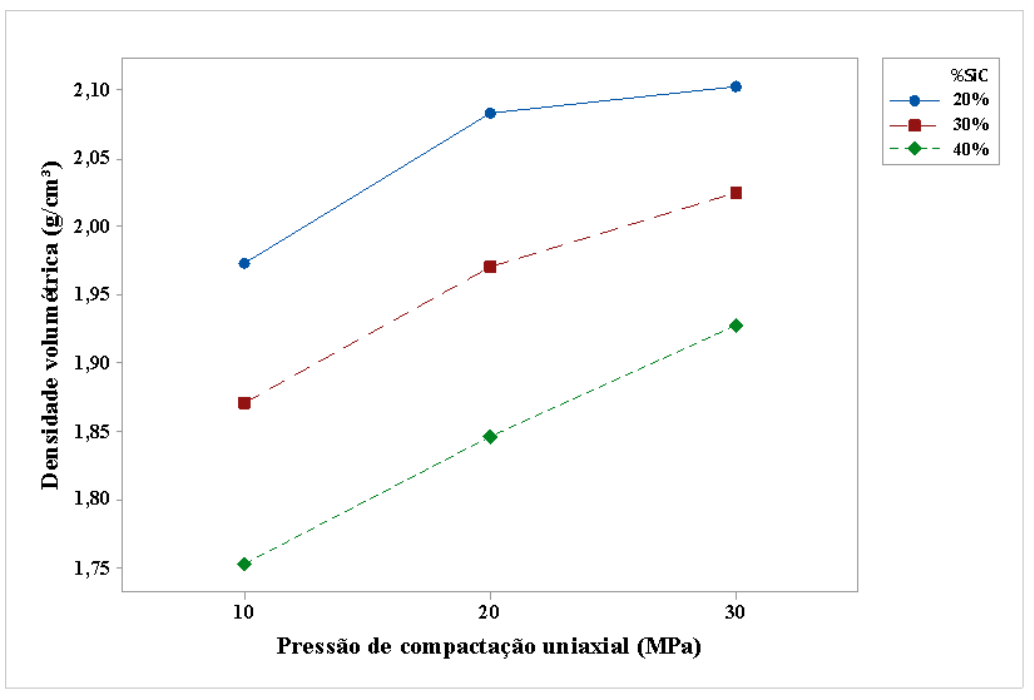

Figura 3. Gráfico de efeitos de interação para densidade volumétrica $\left(\mathrm{g} / \mathrm{cm}^{3}\right)$.

Como pode ser observado, a densidade volumétrica aumenta com a pressão de compactação, que é o esperado, pois a compactação afeta o empacotamento do sistema de partículas, reduzindo a porosidade. Por outro lado, a densidade diminui com o aumento do percentual de carbeto de silício.

\subsection{Porosidade aparente}

A Figura 4 exibe o gráfico de efeitos de interação entre os fatores fração mássica de micropartículas de carbeto de silício e pressão de compactação uniaxial sobre a média da porosidade aparente dos compósitos. 

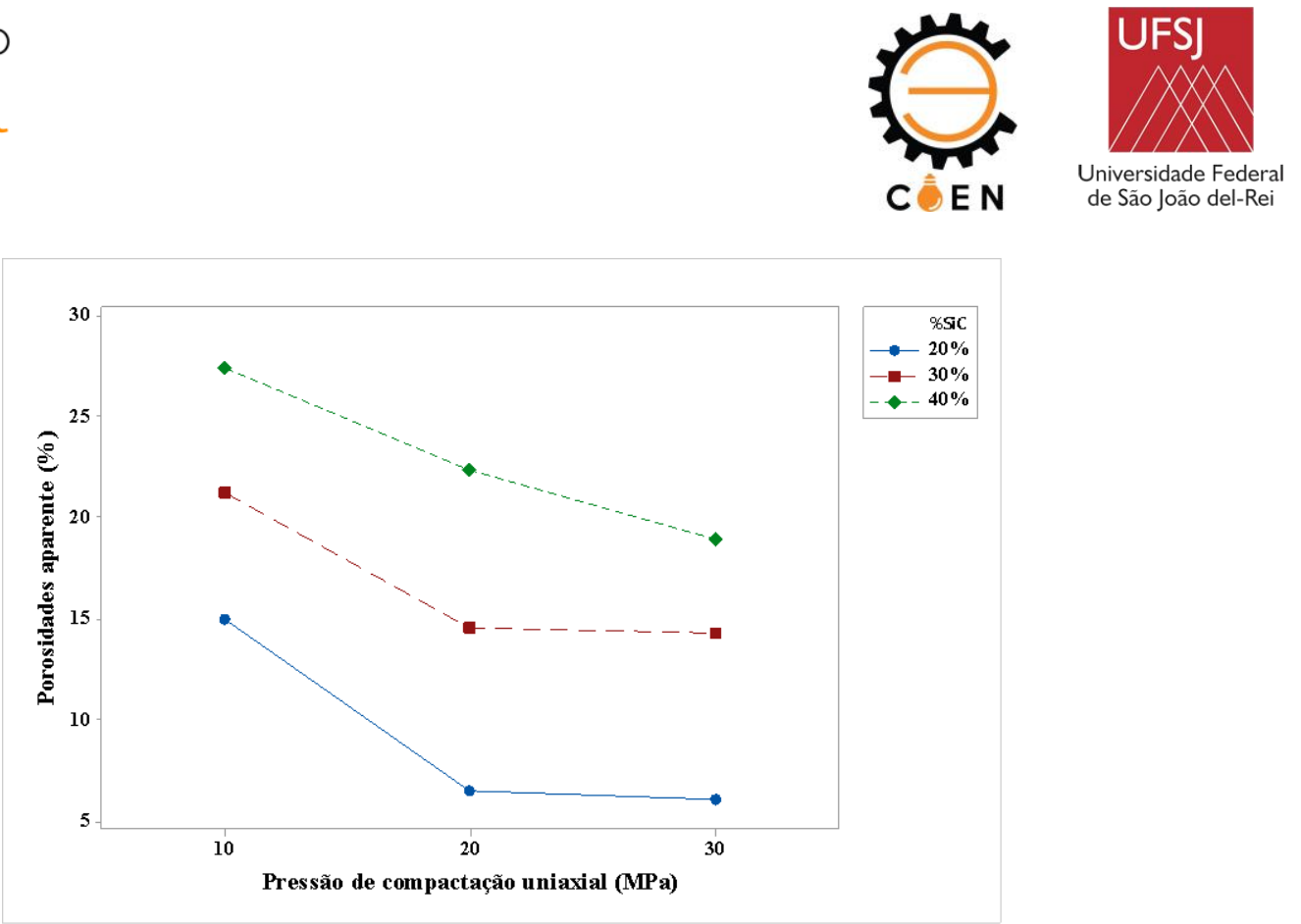

Figura 4. Gráfico de efeitos de interação para porosidade aparente (\%).

É observada redução da porosidade aparente com o aumento da pressão de compactação, sendo mais acentuada entre o nível inferior e o intermediário de compactação, visto que a compactação afeta o empacotamento das partículas, tanto de $\mathrm{SiC}$, quanto de cimento. Observa-se uma menor redução da porosidade entre a compactação com $20 \mathrm{MPa}$ e $30 \mathrm{MPa}$, principalmente para as frações de carbeto de silício de $20 \%$ e $30 \%$. Os resultados revelam também o aumento da porosidade com o aumento no percentual de carbeto de silício. Contudo, de acordo com o efeito da interação, é possível a obtenção de níveis de porosidade equivalentes, variando-se a fração mássica de carbeto de silício juntamente com a variação da pressão de compactação.

\subsection{Resistência à flexão}

A Figura 5 exibe o gráfico de efeitos de interação entre os fatores fração mássica de micropartículas de carbeto de silício e pressão de compactação uniaxial sobre a média da resistência à flexão dos compósitos.

Observa-se, de um modo geral, o aumento da resistência à flexão com o acréscimo da pressão de compactação, uma vez que o material torna-se mais denso e menos poroso nestas condições. Este aumento é mais pronunciado para as maiores frações de carbeto de silício (30\% e $40 \%)$. Para o nível mais baixo deste fator $(\% \mathrm{SiC}=20 \%)$, os resultados mostram ligeira redução de resistência à flexão quando a compactação foi realizada em níveis acima de $20 \mathrm{MPa}$. 


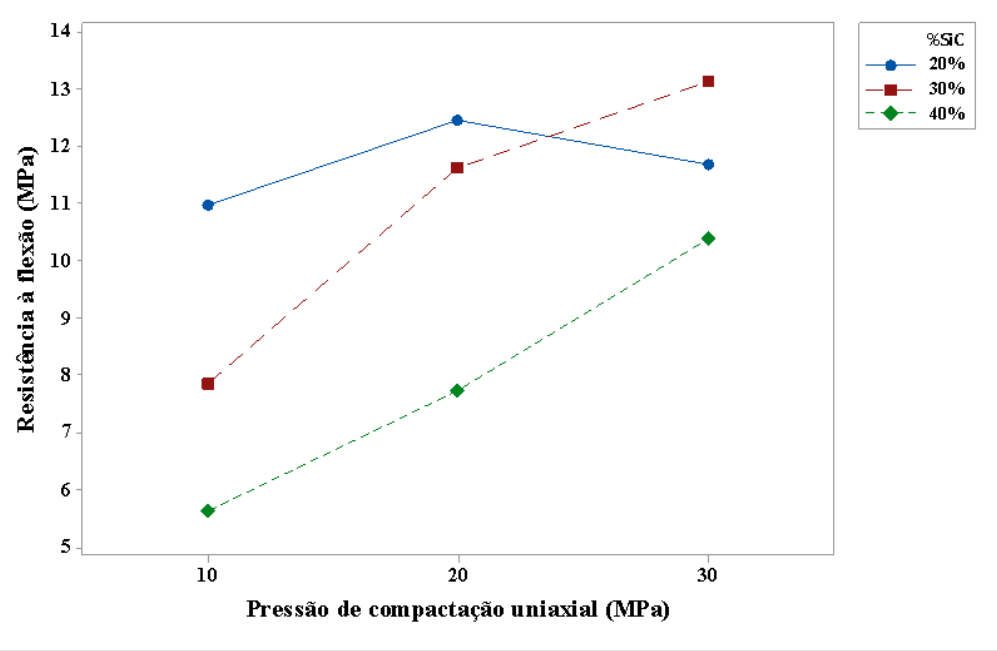

Figura 5. Gráfico de efeitos de interação para resistência à flexão (MPa).

O efeito da fração de carbeto de silício, quando aumentada, é mais pronunciado nos compósitos produzidos com níveis mais baixos de compactação uniaxial. Para o nível mais elevado deste fator (30 MPa) a variação nos resultados de resistência à flexão se mostrou ocorrer em menor intensidade, sendo que o nível intermediário de adição de carbeto do silício (30\%) apresentou a maior resistência mecânica.

A aplicação do material como restritor poroso em mancais aerostáticos exige um balanço entre a porosidade (volume de poros abertos) do material e sua resistência mecânica. Baseado nos resultados de resistência à flexão e porosidade aparente, é possível observar que maiores níveis de pressão de compactação uniaxial devem ser utilizados para maiores frações de adição de micropartículas de carbeto de silício, uma vez que a resistência mecânica é melhorada sem, contudo, produzir redução severa nos níveis de porosidade, além do valor esperado desta propriedade física para a aplicação do material como restritor poroso, de no mínimo $15 \%$ de porosidade, como estabelecido por Panzera et al. (2013). Porém, maiores investigações devem ser realizadas em termos da permeabilidade dos compósitos cimentícios produzidos com carbeto de silício, já que esta propriedade física é fundamental para a aplicação pretendida.

\subsection{Módulo de elasticidade estático}

A Figura 6 exibe o gráfico de efeitos principais dos fatores percentual de carbeto de silício e pressão de compactação uniaxial sobre a média do módulo de elasticidade estático dos compósitos. 


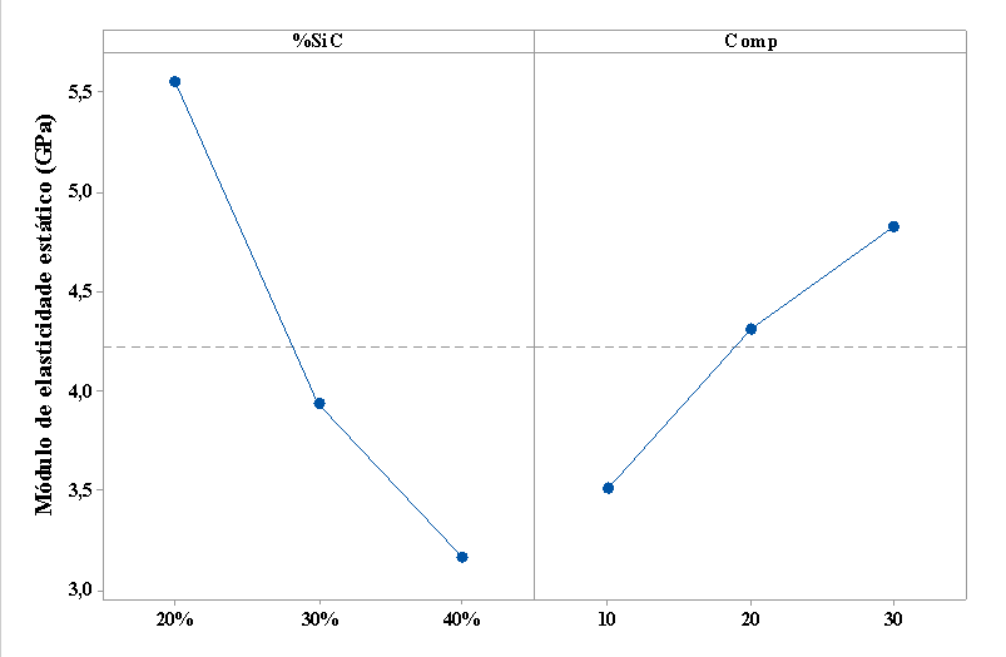

Figura 6. Gráficos de efeitos principais para módulo de elasticidade estático (GPa).

Os resultados exibidos na Figura 6 mostram que o aumento da pressão de compactação eleva a rigidez do compósito, devido à redução da porosidade e aumento da densidade do material. Por outro lado, pode ser observado que o módulo de elasticidade foi reduzido drasticamente com o aumento do percentual de carbeto de silício, principalmente entre os níveis mínimo e intermediário deste fator. Em solicitações mecânicas de flexão há uma combinação de esforços trativos e compressivos atuando no material. Assim, o aumento na quantidade de partículas utilizadas no compósito não produziu aumento da rigidez do material, uma vez que as partículas são prejudiciais quando o material é submetido a tração. Em compressão pura, espera-se que, embora haja aumento da porosidade do material com o aumento na fração de partículas reforçadoras, a rigidez dos compósitos seja maior para maiores percentuais de fase reforçadora particulada, ou que a rigidez não seja diminuída em grande escala.

A partir da análise feita sobre os resultados pode-se chegar a diversas conclusões, que estão listadas a seguir:

- O fator principal "percentual de carbeto de silício" apresentou influência significativa sobre as seguintes variáveis respostas: densidade volumétrica; porosidade aparente; resistência à flexão; módulo de elasticidade estático. Dentre os corpos de prova estudados, os que apresentam melhores valores de resistência à flexão foram os com porcentagens de carbeto de silício de $20 \%$ e $30 \%$. Porém apenas os fabricados com $30 \%$ de carbeto de silício apresentaram valores aceitáveis de porosidade aparente.

- O fator principal "pressão de compactação" apresentou influência significativa sobre as seguintes variáveis respostas: densidade volumétrica; porosidade aparente; resistência à flexão; módulo de elasticidade estático. Os maiores valores de resistência à flexão são encontrados nos corpos de prova fabricados com pressão de 

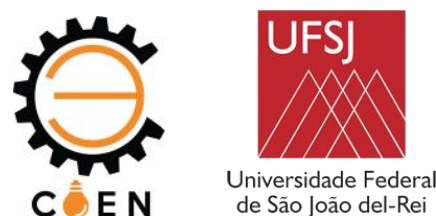

compactação de $30 \mathrm{MPa}$, porém esta condição também entrega os menores valores de porosidade aparente.

- A interação entre os fatores "percentual de carbeto de silício e pressão de compactação" apresentou influência significativa sobre as seguintes variáveis respostas: densidade volumétrica; porosidade aparente; resistência à flexão. A interação entre os fatores mostra que a pressão de compactação trás mais benefícios aos compósitos com nível intermediário de percentual de carbeto de silício (30\%), referentes à resistência à flexão, uma vez que no menor nível de pressão de compactação (10 MPa) os valores desta variável eram baixos, porém alcança os maiores valores estudados no maior nível de pressão de compactação (30 MPa). Também é visto que os valores de porosidade sofrem pouca variação quando o fator pressão de compactação passa do nível intermediário (20 MPa) para o maior nível, para níveis de percentual de carbeto de silício mínimo e intermediário $(20 \%$ e $30 \%$, respectivamente).

- Em relação à porosidade aparente, apenas os corpos de prova com as condições $20 \%$ de percentual de carbeto de silício e pressão de compactação de $20 \mathrm{MPa}$ e $30 \mathrm{MPa}$ não alcançam valores mínimos de $15 \%$.

De acordo com os níveis testados para os fatores experimentais deste trabalho, o compósito que se mostrou mais adequado é aquele produzido com $30 \%$ de carbeto de silício e compactado com $30 \mathrm{MPa}$ de pressão uniaxial, que apresentou porosidade aparente superior a $15 \%$, e o maior nível de resistência à flexão. Deste modo, baseado nos resultados obtidos neste estudo, novos níveis de adição de carbeto de silício (entre $20 \%$ e $40 \%$ ) devem ser estudados visando obter máxima resistência à flexão, dentro dos níveis de porosidade e permeabilidade necessários para a aplicação como restritor poroso.

\section{AGRADECIMENTOS}

Agradeço à CAPES, que proporcionou bolsa auxílio mestrado, sem a qual não seria possível a realização deste trabalho.

Agradeço à empresa Saint-Gobain (unidade Barbacena), que forneceu o carbeto de silício utilizado no estudo.

Agradeço ao professor Dr. Leandro José da Silva, pela orientação e apoio ao longo dos estudos realizados.

Agradeço aos técnicos dos laboratórios que foram de grande ajuda durante os processos de fabricação e ensaio dos materiais

\section{DIREITOS AUTORAIS.}

Os autores são os únicos responsáveis pelo conteúdo das informações contidas neste artigo.

\section{REFERÊNCIAS}



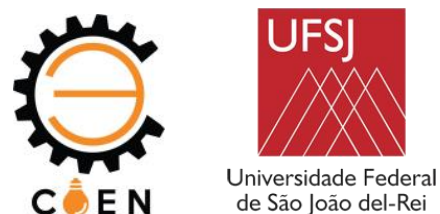

ASTM International C1161-13: Standard Test Method for Flexural Strength of Advanced Ceramics at Ambient Temperature, 2013.

BAHARI, A.; BERENJIAN, J.; SADEGHI-NIK, A. Modification of Portland cement with nano SiC. Proceeding of the National Academy of Sciences, India Section A, v. 86, n. 3, p. 323-331, jul./set. 2016.

BRITISH STANDARD. BS 1881-114: Testing concrete. Methods for determination of density of hardened concrete, 1983.

FOURKA, M.; BONIS, M. Comparison between externally pressurized gas thrust bearings with different orifice and porous feeding systems. Wear, v. 210, p. 311-317, 1997.

KWAN, Y. B. P. Processing and fluid flow characteristics of hot isostatically pressed porous alumina for aerostatic bearing applications. 1996. 425 p. Ph.D. Thesis - Cranfield Institute of Technology, United Kingdom, 1996.

MUNDAY, A. J. A review of externally pressurised gas bearings. In: A joint conference arranged by the Tribology Group of the Institution of Mechanical Engineers and the Institution of Production Engineers, Westminster, London, 1971.

OHJI, T. et al. Particle/Matrix Interface and its role in creep inhibition in Alumina/Silicon Carbide nanocomposites. Journal of the American Ceramic Society, v. 79, n. 1, p. 33-45, 1996.

PANZERA, T. H. Desenvolvimento de um material compósito cerâmico para aplicação em mancais porosos. 2007, 193 p. Tese (Doutorado). Programa de Pós-graduação em Engenharia Mecânica da Universidade Federal de Minas Gerais, Universidade Federal de Minas Gerais, Belo Horizonte - MG.

PANZERA, T. H. et al. Evaluation of compacted cementitious composites for porous bearings. International Journal of Applied Ceramic Technology, v. 10, n. 3, p. 474-483, mai./jun. 2013.

SILVA, L. J. Mancais aerostáticos porosos fabricados em compósito cimentício reforçado com nanotubos de carbono. 2015207 p. Tese (Doutorado). Programa de Pós-graduação em Engenharia Mecânica da Universidade Federal de Minas Gerais, Universidade Federal de Minas Gerais, Belo Horizonte - MG.

TANAKA, H. Silicon carbide poder and sintered materials. Journal of the Ceramic Society of Japan, Tokyo, v. 119, n. 3, p. 218-233, dez. 2011.

XIE, Y. et al. Effect of SiC Particles on Mechanical Properties of Laminated $\left(\mathrm{SiC}_{\mathrm{w}}+\mathrm{SiC} \mathrm{p}\right) / \mathrm{SiC}$ Ceramic Composites. International Journal of Applied Ceramic Technology, Tokyo, v. 12, n. 3, p. 535-541, 2015.

\section{CEMENT MATRIX COMPOSITE MATERIAL REINFORCED WITH SILICON CARBIDE PARTICLES AS POROUS RESTRICTOR IN AEROSTATIC BEARINGS}

Heitor Camargo Melo ${ }^{(1)}$ (heitorcmelo@outlook.com), Leandro José da Silva ${ }^{(2)}$ (leandro.silva@ ufsj.edu.br)

${ }^{(1)}$ Universidade Federal de São João del-Rei (UFSJ) - PPMEC - Praça Frei Orlando, 170, Centro, São João del-Rei, Minas Gerais

(2) Universidade Federal de São João del-Rei (UFSJ) - DEMEC - Praça Frei Orlando, 170, Centro, São João del-Rei, Minas Gerais

ABSTRACT: This work's main objective is to investigate the influence of the addition of silicon carbide (SiC) and the compaction pressure, during manufacturing, on the physical and mechanical properties of a 
cement matrix composite, with the purpose of developing a material that delivers levels of porosity and mechanical resistance suitable for use in a aerostatic bearing. The full factorial planning methodology was used to study the effects of the SiC mass fraction and the compaction pressure on the composites' bulk density, apparent porosity, flexural strength and static modulus of elasticity. The preliminary experiments were conducted by evaluating three levels for the addition of SiC microparticles (20\%, 30\% and 40\%) and three compaction levels of the composites (10 MPa, $20 \mathrm{MPa}$, and $30 \mathrm{MPa})$. The preliminary results show that both factors, SiC mass fraction and compaction pressure, in addition to the interaction between factors, have a significant influence on the results of the studied properties.

KEYWORDS: Silicon carbide, Cement matrix copmposite, Aerostatic bearings, Uniaxial compaction. 